Review

\title{
Retardation of Myopia Progression by Multifocal Soft Contact Lenses
}

\author{
Qin Zhu ${ }^{1}$, Yongsong $\mathrm{Liu}^{2}$, Sean Tighe ${ }^{3}$, Yingting $\mathrm{Zhu}^{3}$, Xuanbo Su${ }^{1}$, Fabing $\mathrm{Lu}^{1}$ and $\mathrm{Min} \mathrm{Hu}^{1 凶}$ \\ 1. Department of Ophthalmology, Fourth Affiliated Hospital of Kunming Medical University (the Second People's Hospital of Yunnan Province); Yunnan \\ Eye Institute; Key Laboratory of Yunnan Province for the Prevention and Treatment of ophthalmology (2017DG008); Provincial Innovation Team for \\ Cataract and Ocular Fundus Disease, The Second People's Hospital of Yunnan Province (2017HC010); Expert Workstation of Yao Ke \\ (2017IC064), Kunming 650021, China \\ 2. Yan'An Hospital of Kunming City, Kunming 650051, China \\ 3. Tissue Tech, Inc., Ocular Surface Center, and Ocular Surface Research \& Education Foundation, Miami, FL, 33173 USA
}

$\square$ Corresponding author: Min Hu, M.D., Ph.D. Department of Ophthalmology, Fourth Affiliated Hospital of Kunming Medical University, Second People's Hospital of Yunnan Province, Kunming 650021, China; Telephone: 0118615087162600; Fax: 011860871-65156650; E-mail: fudanhumin@sina.com

(C) Ivyspring International Publisher. This is an open access article distributed under the terms of the Creative Commons Attribution (CC BY-NC) license (https://creativecommons.org/licenses/by-nc/4.0/). See http://ivyspring.com/terms for full terms and conditions.

Received: 2018.09.21; Accepted: 2018.12.07; Published: 2019.01.01

\begin{abstract}
Myopia is an important public health problem due to its prevalence and significant public health cost. Elevating levels of myopia increase the risk of vision impairment, and therefore, high myopia has become one of the main causes of untreatable vision loss throughout the world due to its irreversible complications. At present, many options for slowing progression of myopia have already been proposed and evaluated such as progressive addition of executive bifocal spectacle lenses, peripheral defocusing lenses, overnight orthokeratology, pharmacological agents such as atropine eye drops, and multifocal soft contact lenses (MFSCLs). Use of MFSCLs has especially increased in recent years due to the growing demand to slow myopia progression during patient's adolescent growth period to avoid pathological myopia in adulthood. Compared with the other traditional methods of controlling myopia, MFSCLs allow myopic patients to better maintain their clear visual quality and slow myopia progression. In this manuscript, we aim to review the basics of myopia, recent advances in contact lenses to control myopia with emphasis on MFSCLs, define the elements for proper MFSCL fittings (such as pupil size, aberrations, accommodation and centering), discuss the potential rebound effect after discontinuation of contact lenses, and future directions for improvements of contact lenses for the control of myopia.
\end{abstract}

Key words: Multifocal soft contact lenses, Myopia, Progression

\section{Prevalence and Risking Factors of Myopia}

Myopia is traditionally considered as mere refractive error. However, recent increased prevalence in the world, especially in Asia, has forced the scientific society to view it differently [1-5]. The incidence of myopia is $\sim 95 \%$ in the youngster population from China/ Korea $[1,2]$ and can occur when children are as young as 5-6 years old [6-8]. The most common form of myopia worldwide is secondary to elongation of the axial length of the eye, termed axial myopia. This axial lengthening process begins in childhood and progresses remarkably during the adolescent growth period [9]. Data from China, Taiwan and Japan indicate that severe axial myopia has become one of the main causes of untreatable vision loss throughout the world, often due to its irreversible complications, such as retinal detachment, macular degeneration, macular hemorrhage, choroidal neovascularization and open angle glaucoma [10, 11]. It was estimated that 1.5 billion people were affected in 2010, but this number is expected to rise to 5 billion by 2050 [4]. Unfortunately, this disease has no definitive cure by traditional optical interventions.

\section{Historical Treatments of Myopia}

At present, many options for slowing progression of myopia have been proposed and evaluated, such as progressive addition of executive bifocal spectacle lenses [12-14], peripheral defocusing lenses [15], contact lenses [16], outdoor activities [17], 
pharmacological agents such as atropine eyedrops [18],overnight orthokeratology [19-21], and multifocal soft contact lenses [22]. However a Cochrane Database Systematic Review in 2011 concluded that bifocals, progressive addition lenses and contact lenses yield disappointing long term results for myopia control [15] and specially designed spectacle lenses have minimal effect [23]. Atropine eyedrops which seem to be an effective way to slow the progression of myopia are also limited by drug side effects such as photophobia, abnormal accommodation and myopic rebound. Another alternative are certain specially designed contact lenses including orthokeratology and multifocal soft contact lenses (MFSCLs) which have been shown to delay induced myopia progression by generally incorporating 'positive power' to reduce the hyperopic defocus and/or impose myopic defocus in peripheral retina [24-27]. A study showed lenses with myopic defocus in the peripheral retina delay axial length elongation [28], while lenses imposing peripheral hyperopic defocus have the opposite effect, increasing the rate of elongation [24, 27]. These findings encourage the use of the optical devices for myopia control. While orthokeratology is an effective tool in delaying axial elongation $[19,29]$, children have to sleep with lenses at least 8-10 hours for necessary corneal curvature and orthokeratology is only applicable to the children with low and moderate myopia.

\section{Slowing Myopia Progression by Use of Contact Lenses}

Among all treatment options for myopia, soft contact lenses (SCLs) have been extensively investigated for their effect on retarding myopia progression since 1970s [30]. As early as 1975, contact lenses were considered to slow myopia progression when rigid contact lenses were shown to slow down myopia progression compared to spectacles as the control [31]. A later study in 1990s suggested rigid gas-permeable (RGP) contact lenses slowed myopia progression compared to spectacle lenses. More recently, SCLs designed with new materials and technologies (e.g. concentric ring bifocal SCLs [32-34] or peripheral add multifocal SCLs [35-39]) have achieved significant success in retarding myopia progression in pre-school- and school-age children. The design of concentric ring bifocal SCLs consists of a central distance zone surrounded by correction zones with near addition, while peripheral add multifocal SCLs arecomposed of a central zone for distance vision surrounded by progressivelyincreased relative positive power in peripheral zones. These specifically-designed SCLs are promising.
Although contact lenses are a promising, effective and attractive method for myopia control, wearing contact lenses is not always beneficial. The key controversial issue of wearing contact lenses is associated with safety. In children with contact lenses, drawbacks have been noted, similar to those reported in adult contact lenses wearers [40-43]. One of the most common risks is microbial keratitis as observed in many overnight wearers. Furthermore, discomfort could complicate the effective usage of contact lenses for control of myopia [44]. In fact, compliance with wearing lenses was found to be critical in retarding progression of myopia [45]. Among non-presbyopic myopic wearers, lenses featuring multifocality might decrease visual performance due to large power variations in the optic zone or when the lenses were decentered [46].

\section{Better Control of Myopia by Defocus of Multifocal Soft Contact Lenses}

Contact lenses are ideal for myopic defocus of $360^{\circ}$ in the periphery area since the lenses are relatively centered during eye movements. Investigations in myopic children with orthokeratology lenses have suggested decreases in axial elongation [47-51]. The decrease of axial growth with orthokeratology is probably due to myopic shift in the peripheral area of retinal defocus led by changes of corneal shape stimulated by the lenses [52-54]. Other reports have suggested that soft bifocal contact lenses might slow down myopia progression in a short period in school children $[55,56]$. However, no results from a multi-year clinical trial with soft bifocal contact lenses are currently available, and myopic shift due to peripheral defocus by soft bifocal contact lenses has been debated previously $[54,57]$.

Hyperopic retinal defocus in the peripheral area was first indicated as a potential mechanism for myopia progression in the 1970s [58]. Since that time, the results from several animal and human clinical studies have strongly suggested that retinal defocus in the peripheral area might mediate eye growth even under a clear foveal image [24, 59], and optical lenses eliminating hyperopic defocus in the peripheral area or inducing myopic defocus in the peripheral area might retard the progression of myopia in school children [60]. These results indicate that optical designs with myopic defocus may be a feasible option for delaying myopia progression.

Although eye response to optical defocus has been described in animal studies, it is still unknown how the optical signals are activated or inhibited in choroid, retina and sclera, and how the signals control structural changes that cause increased axial length. Until recently, various hypotheses have been 
proposed to explain the myopia control effect of these lenses, including:

$\operatorname{lag}[61]$

1. reduction and correction of accommodative

2. positional alteration of the peripheral retinal image for decrease of hyperopic defocus [56];

3. imposition of extended myopic defocus in the retina $[45,55]$;

4. elimination of the hyperopic blur induced by negative spherical aberration in accommodation [40];

5. alteration and optimization of the quality of retinal image for the points in front of the retina and degrading quality of retinal image for the points behind the retina [62].

These hypotheses require further investigations, of course.

\section{Contact Lens Designs}

Some multi-zone, presbyopic contact lenses have been developed for myopia control through removing hyperopic defocus [55, 61, 63, 64]. However, the ability to remove hyperopic defocus by such multizone contact lenses mainly depends on the behavior in eyes with these lenses [55, 65]. That is, when the eyes relax their accommodation, the anticipated defocus may not happen. Nevertheless, compared to the power transition from distance to near that happens with spectacles, MFSCLs can provide near and distance correction in the pupil, therefore, offering constant exposure to the treatment zone and at the same time, correcting the compliance shortcoming of spectacle options. In fact, increased accommodative lag is associated with myopia progression [66-69], indicating that accommodative lag may promote progression of myopia.

Extended depth of focus (EDOF) through manipulation of contact lenses magnitude may further improve contact lenses [70]. EDOF [70] design has the advantage that power distribution changes gradually from distance to near power, in contrast to the power distribution of center-distance and center-near aspheric multifocal contact lenses, monotonic in nature. For example, EDOF lenses have provided significant improvement of intermediate and near vision without adversely affecting distance vision [70]. Moreover, progressive designs [56] of multifocal soft contact lenses with ADD (which manipulate the distance correction towards the peripheral area) have been adopted recently [45, 55]. MFSCLs are advantageous compared to overnight orthokeratology and atropine eyedrops as they reduce the risk of microbial keratitis and reduce side effects, respectively.

\section{Parameters that may Affect Fitting and Clinical Outcome, Limitations and Future Directions}

Parameters that may Affect Fitting and Clinical Outcome: (1) Wearing Time: Wearing time is an important factor to retard myopia progression by MFSCLs [45]. In this article, it is suggested that the optimal wearing time for the MFSCLs lens is 7-8 hours per day to achieve the retardation up to $58 \%$. (2) Different ADD: It is reported that the better myopia control effect may be achieved with higher add powers [71]. (3) Pupil size: Pupil size has a significant effect on MFSCLs performance [72]. Previous studies [73-75] have suggested that the refractive power by MFSCLs varies with the pupil size and across individuals. This is critical since people with the same visual requirements may have varying visual performance when fitted with the same MFSCLs as a result of different pupil size.

Limitations: Potential limitations include: randomized controlled trials have different parameters and bias is present [76]. Bias may also come from ethnicity. For example, the effect of SCLs on retarding myopia in Asian children is more significant [77, 78]. As most of the studies have suggested, children with low myopia are often included and observed them with various follow-up periods.

Future Directions: Regarding to rebound of myopia due to discontinuation of lens wear, no reports have been noted for monitoring the progression of myopia due to discontinuation of wear of soft contact lens. Further studies are required for myopia rebound due to discontinuation of wear of soft contact lens. In addition, the safety of MFSCLs requires further studies. Furthermore, MFSCLs should be carefully designed with lower compromising for image quality.

\section{Conclusion}

Multifocal contact lenses slow progression of myopia and are one of the most effective methods to control myopia to date. Nevertheless, questions remain on the mechanism of how these lenses improve and retain vision. Further research and development is needed in designing contact lenses for younger patients, as there is an elevated prevalence of myopia in school-age children. Eye doctors should consider the benefits and risks of multifocal contact lenses compared to other options.

\section{Acknowledgements}

Supported by the National Natural Science Foundation of China, Grant No. 81560168. 


\section{Competing Interests}

The authors have declared that no competing interest exists.

\section{References}

1. Jung SK, Lee JH, Kakizaki H, Jee D. Prevalence of myopia and its association with body stature and educational level in 19-year-old male conscripts in seoul, South Korea. Invest Ophthalmol Vis Sci. 2012; 53: 5579-83.

2. Sun J, Zhou J, Zhao P, Lian J, Zhu H, Zhou Y, et al. High prevalence of myopia and high myopia in 5060 Chinese university students in Shanghai. Invest Ophthalmol Vis Sci. 2012; 53: 7504-9.

3. Holden B, Sankaridurg P, Smith E, Aller T, Jong M, He M. Myopia, an underrated global challenge to vision: where the current data takes us on myopia control. Eye (Lond). 2014; 28: 142-6.

4. Holden BA, Fricke TR, Wilson DA, Jong M, Naidoo KS, Sankaridurg P, et al. Global Prevalence of Myopia and High Myopia and Temporal Trends from 2000 through 2050. Ophthalmology. 2016; 123: 1036-42.

5. Williams KM, Verhoeven VJ, Cumberland P, Bertelsen G, Wolfram C, Buitendijk $\mathrm{GH}$, et al. Prevalence of refractive error in Europe: the European Eye Epidemiology (E(3)) Consortium. Eur J Epidemiol. 2015; 30: 305-15.

6. Lam CS, Edwards M, Millodot M, Goh WS. A 2-year longitudinal study of myopia progression and optical component changes among Hong Kong schoolchildren. Optom Vis Sci. 1999; 76: 370-80.

7. Lam CS, Goldschmidt E, Edwards MH. Prevalence of myopia in local and international schools in Hong Kong. Optom Vis Sci. 2004; 81: 317-22.

8. Lim MC, Gazzard G, Sim EL, Tong L, Saw SM. Direct costs of myopia in Singapore. Eye (Lond). 2009; 23: 1086-9.

9. Tideman JWL, Polling JR, Vingerling JR, Jaddoe VWV, Williams C, Guggenheim JA, et al. Axial length growth and the risk of developing myopia in European children. Acta Ophthalmol. 2018; 96: 301-9.

10. Iwase A, Araie M, Tomidokoro A, Yamamoto T, Shimizu H, Kitazawa Y, et al. Prevalence and causes of low vision and blindness in a Japanese adult population: the Tajimi Study. Ophthalmology. 2006; 113: 1354-62.

11. Hsu WM, Cheng CY, Liu JH, Tsai SY, Chou P. Prevalence and causes of visual impairment in an elderly Chinese population in Taiwan: the Shihpai Eye Study. Ophthalmology. 2004; 111: 62-9.

12. Gwiazda J, Hyman L, Hussein M, Everett D, Norton TT, Kurtz D, et al. A randomized clinical trial of progressive addition lenses versus single vision lenses on the progression of myopia in children. Invest Ophthalmol Vis Sci. 2003; 44: 1492-500.

13. Hasebe S, Ohtsuki H, Nonaka T, Nakatsuka C, Miyata M, Hamasaki I, et al. Effect of progressive addition lenses on myopia progression in Japanese children: a prospective, randomized, double-masked, crossover trial. Invest Ophthalmol Vis Sci. 2008; 49: 2781-9.

14. Berntsen DA, Sinnott LT, Mutti DO, Zadnik K. A randomized trial using progressive addition lenses to evaluate theories of myopia progression in children with a high lag of accommodation. Invest Ophthalmol Vis Sci. 2012; 53: 640-9.

15. Walline JJ, Lindsley K, Vedula SS, Cotter SA, Mutti DO, Twelker JD. Interventions to slow progression of myopia in children. Cochrane Database Syst Rev. 2011: CD004916.

16. Grosvenor T, Perrigin J, Perrigin D, Quintero S. Use of silicone-acrylate contact lenses for the control of myopia: results after two years of lens wear. Optom Vis Sci. 1989; 66: 41-7.

17. Xiong S, Sankaridurg P, Naduvilath T, Zang J, Zou H, Zhu J, et al. Time spent in outdoor activities in relation to myopia prevention and control: a meta-analysis and systematic review. Acta Ophthalmol. 2017; 95: 551-66.

18. Gwiazda J. Treatment options for myopia. Optom Vis Sci. 2009; 86: 624-8

19. Cho P, Cheung SW. Retardation of myopia in Orthokeratology (ROMIO) study: a 2-year randomized clinical trial. Invest Ophthalmol Vis Sci. 2012; 53: 7077-85.

20. Sun Y, Xu F, Zhang T, Liu M, Wang D, Chen Y, et al. Orthokeratology to control myopia progression: a meta-analysis. PLoS One. 2015; 10: e0124535.

21. Chan DK, Fung YK, Xing S, Hagger MS. Myopia prevention, near work, and visual acuity of college students: integrating the theory of planned behavior and self-determination theory. J Behav Med. 2014; 37: 369-80.

22. Kang P, McAlinden C, Wildsoet CF. Effects of multifocal soft contact lenses used to slow myopia progression on quality of vision in young adults. Acta Ophthalmol. 2017; 95: e43-e53.

23. Huang J, Wen D, Wang $\mathrm{Q}$, McAlinden $\mathrm{C}$, Flitcroft I, Chen $\mathrm{H}$, et al. Efficacy Comparison of 16 Interventions for Myopia Control in Children: A Network Meta-analysis. Ophthalmology. 2016; 123: 697-708.

24. Smith EL, 3rd, Hung LF, Huang J. Relative peripheral hyperopic defocus alters central refractive development in infant monkeys. Vision Res. 2009; 49: 2386-92.

25. Liu $Y$, Wildsoet $C$. The effective add inherent in 2-zone negative lenses inhibits eye growth in myopic young chicks. Invest Ophthalmol Vis Sci. 2012; 53: 5085-93.

26. Benavente-Perez A, Nour A, Troilo D. The effect of simultaneous negative and positive defocus on eye growth and development of refractive state in marmosets. Invest Ophthalmol Vis Sci. 2012; 53: 6479-87.
27. Benavente-Perez A, Nour A, Troilo D. Axial eye growth and refractive error development can be modified by exposing the peripheral retina to relative myopic or hyperopic defocus. Invest Ophthalmol Vis Sci. 2014; 55: 6765-73.

28. Liu Y, Wildsoet $\mathrm{C}$. The effect of two-zone concentric bifocal spectacle lenses on refractive error development and eye growth in young chicks. Invest Ophthalmol Vis Sci. 2011; 52: 1078-86.

29. Siatkowski RM, Cotter SA, Crockett RS, Miller JM, Novack GD, Zadnik K, et al. Two-year multicenter, randomized, double-masked, placebo-controlled, parallel safety and efficacy study of $2 \%$ pirenzepine ophthalmic gel in children with myopia. J AAPOS. 2008; 12: 332-9.

30. Grosvenor T, Perrigin D, Perrigin J, Quintero S. Rigid gas-permeable contact lenses for myopia control: effects of discontinuation of lens wear. Optom Vis Sci. 1991; 68: 385-9.

31. Kelly TS, Chatfield C, Tustin G. Clinical assessment of the arrest of myopia. Br J Ophthalmol. 1975; 59: 529-38.

32. Diether S, Schaeffel F. Local changes in eye growth induced by imposed local refractive error despite active accommodation. Vision Res. 1997; 37: 659-68.

33. Dumbleton KA, Chalmers RL, Richter DB, Fonn D. Changes in myopic refractive error with nine months' extended wear of hydrogel lenses with high and low oxygen permeability. Optom Vis Sci. 1999; 76: 845-9.

34. Jalbert I, Stretton S, Naduvilath T, Holden B, Keay L, Sweeney D. Changes in myopia with low-Dk hydrogel and high-Dk silicone hydrogel extended wear. Optom Vis Sci. 2004; 81: 591-6.

35. Harris MG, Sarver MD, Polse KA. Corneal curvature and refractive error changes associated with wearing hydrogel contact lenses. Am J Optom Physiol Opt. 1975; 52: 313-9.

36. Horner DG, Soni PS, Salmon TO, Swartz TS. Myopia progression in adolescent wearers of soft contact lenses and spectacles. Optom Vis Sci. 1999; 76: 474-9.

37. Walline JJ, Jones LA, Sinnott L, Manny RE, Gaume A, Rah MJ, et al. A randomized trial of the effect of soft contact lenses on myopia progression in children. Invest Ophthalmol Vis Sci. 2008; 49: 4702-6.

38. Kwok E, Patel B, Backhouse S, Phillips JR. Peripheral refraction in high myopia with spherical soft contact lenses. Optom Vis Sci. 2012; 89: 263-70.

39. Shen J, Clark CA, Soni PS, Thibos LN. Peripheral refraction with and without contact lens correction. Optom Vis Sci. 2010; 87: 642-55.

40. Cheng X, Xu J, Chehab K, Exford J, Brennan N. Soft Contact Lenses with Positive Spherical Aberration for Myopia Control. Optom Vis Sci. 2016; 93: 353-66.

41. Sankaridurg P, Chen X, Naduvilath T, Lazon de la Jara P, Lin Z, Li L, et al. Adverse events during 2 years of daily wear of silicone hydrogels in children. Optom Vis Sci. 2013; 90: 961-9.

42. Chalmers RL, Hickson-Curran SB, Keay L, Gleason WJ, Albright R. Rates of adverse events with hydrogel and silicone hydrogel daily disposable lenses in a large postmarket surveillance registry: the TEMPO Registry. Invest Ophthalmol Vis Sci. 2015; 56: 654-63.

43. Chalmers RL, Wagner H, Mitchell GL, Lam DY, Kinoshita BT, Jansen ME, et al. Age and other risk factors for corneal infiltrative and inflammatory events in young soft contact lens wearers from the Contact Lens Assessment in Youth (CLAY) study. Invest Ophthalmol Vis Sci. 2011; 52: 6690-6.

44. Sulley A, Young G, Hunt C. Factors in the success of new contact lens wearers. Cont Lens Anterior Eye. 2017; 40: 15-24.

45. Lam CS, Tang WC, Tse DY, Tang YY, To CH. Defocus Incorporated Soft Contact (DISC) lens slows myopia progression in Hong Kong Chinese schoolchildren: a 2-year randomised clinical trial. Br J Ophthalmol. 2014; 98: 40-5.

46. Fedtke C, Bakaraju RC, Ehrmann K, Chung J, Thomas V, Holden BA. Visual performance of single vision and multifocal contact lenses in non-presbyopic myopic eyes. Cont Lens Anterior Eye. 2016; 39: 38-46.

47. Walline JJ, Jones LA, Sinnott LT. Corneal reshaping and myopia progression. Br J Ophthalmol. 2009; 93: 1181-5.

48. Cho P, Cheung SW, Edwards M. The longitudinal orthokeratology research in children (LORIC) in Hong Kong: a pilot study on refractive changes and myopic control. Curr Eye Res. 2005; 30: 71-80.

49. Kakita T, Hiraoka T, Oshika T. Influence of overnight orthokeratology on axial elongation in childhood myopia. Invest Ophthalmol Vis Sci. 2011; 52: 2170-4.

50. Santodomingo-Rubido J, Villa-Collar C, Gilmartin B, Gutierrez-Ortega R. Myopia control with orthokeratology contact lenses in Spain: refractive and biometric changes. Invest Ophthalmol Vis Sci. 2012; 53: 5060-5.

51. Hiraoka T, Kakita T, Okamoto F, Takahashi H, Oshika T. Long-term effect of overnight orthokeratology on axial length elongation in childhood myopia: a 5-year follow-up study. Invest Ophthalmol Vis Sci. 2012; 53: 3913-9.

52. Kang $P$, Swarbrick $H$. Peripheral refraction in myopic children wearing orthokeratology and gas-permeable lenses. Optom Vis Sci. 2011; 88: 476-82.

53. Queiros A, Gonzalez-Meijome JM, Jorge J, Villa-Collar C, Gutierrez AR. Peripheral refraction in myopic patients after orthokeratology. Optom Vis Sci. 2010; 87: 323-9.

54. Ticak A, Walline JJ. Peripheral optics with bifocal soft and corneal reshaping contact lenses. Optom Vis Sci. 2013; 90: 3-8.

55. Anstice NS, Phillips JR. Effect of dual-focus soft contact lens wear on axial myopia progression in children. Ophthalmology. 2011; 118: 1152-61.

56. Sankaridurg P, Holden B, Smith E, 3rd, Naduvilath T, Chen X, de la Jara PL, et al. Decrease in rate of myopia progression with a contact lens designed to reduce relative peripheral hyperopia: one-year results. Invest Ophthalmol Vis Sci. 2011; 52: 9362-7. 
57. Rosen R, Jaeken B, Lindskoog Petterson A, Artal P, Unsbo P, Lundstrom L. Evaluating the peripheral optical effect of multifocal contact lenses. Ophthalmic Physiol Opt. 2012; 32: 527-34.

58. Hoogerheide J, Rempt F, Hoogenboom WP. Acquired myopia in young pilots. Ophthalmologica. 1971; 163: 209-15.

59. Irving EL, Callender MG, Sivak JG. Inducing ametropias in hatchling chicks by defocus--aperture effects and cylindrical lenses. Vision Res. 1995; 35: 1165-74.

60. Smith EL, 3rd. Prentice Award Lecture 2010: A case for peripheral optical treatment strategies for myopia. Optom Vis Sci. 2011; 88: 1029-44.

61. Aller TA, Liu M, Wildsoet CF. Myopia Control with Bifocal Contact Lenses: A Randomized Clinical Trial. Optom Vis Sci. 2016; 93: 344-52.

62. Cooper J, O'Connor B, Watanabe R, Fuerst R, Berger S, Eisenberg N, et al. Case Series Analysis of Myopic Progression Control With a Unique Extended Depth of Focus Multifocal Contact Lens. Eye Contact Lens. 2018; 44: e16-e24.

63. Aller TA, Wildsoet C. Bifocal soft contact lenses as a possible myopia control treatment: a case report involving identical twins. Clin Exp Optom. 2008; 91: 394-9.

64. Walline JJ, Greiner KL, McVey ME, Jones-Jordan LA. Multifocal contact lens myopia control. Optom Vis Sci. 2013; 90: 1207-14

65. Altoaimi BH, Almutairi MS, Kollbaum PS, Bradley A. Accommodative Behavior of Young Eyes Wearing Multifocal Contact Lenses. Optom Vis Sci. 2018; 95: 416-27.

66. Gwiazda JE, Hyman L, Norton TT, Hussein ME, Marsh-Tootle W, Manny R, et al. Accommodation and related risk factors associated with myopia progression and their interaction with treatment in COMET children. Invest Ophthalmol Vis Sci. 2004; 45: 2143-51.

67. Gwiazda J, Thorn F, Bauer J, Held R. Myopic children show insufficient accommodative response to blur. Invest Ophthalmol Vis Sci. 1993; 34: 690-4.

68. Abbott ML, Schmid KL, Strang NC. Differences in the accommodation stimulus response curves of adult myopes and emmetropes. Ophthalmic Physiol Opt. 1998; 18: 13-20.

69. Mutti DO, Mitchell GL, Hayes JR, Jones LA, Moeschberger ML, Cotter SA, et al. Accommodative lag before and after the onset of myopia. Invest Ophthalmol Vis Sci. 2006; 47: 837-46.

70. Tilia D, Bakaraju RC, Chung J, Sha J, Delaney S, Munro A, et al. Short-Term Visual Performance of Novel Extended Depth-of-Focus Contact Lenses. Optom Vis Sci. 2016; 93: 435-44.

71. Walline JJ, Gaume Giannoni A, Sinnott LT, Chandler MA, Huang J, Mutti DO, et al. A Randomized Trial of Soft Multifocal Contact Lenses for Myopia Control: Baseline Data and Methods. Optom Vis Sci. 2017; 94: 856-66.

72. Plainis S, Atchison DA, Charman WN. Power profiles of multifocal contact lenses and their interpretation. Optom Vis Sci. 2013; 90: 1066-77.

73. Cardona G, Lopez S. Pupil diameter, working distance and illumination during habitual tasks. Implications for simultaneous vision contact lenses for presbyopia. J Optom. 2016; 9: 78-84.

74. Madrid-Costa D, Ruiz-Alcocer J, Garcia-Lazaro S, Ferrer-Blasco T, Montes-Mico R. Optical power distribution of refractive and aspheric multifocal contact lenses: Effect of pupil size. Cont Lens Anterior Eye. 2015; 38: 317-21.

75. Wagner S, Conrad F, Bakaraju RC, Fedtke C, Ehrmann K, Holden BA. Power profiles of single vision and multifocal soft contact lenses. Cont Lens Anterior Eye. 2015; 38: 2-14

76. Li SM, Wu SS, Kang MT, Liu Y, Jia SM, Li SY, et al. Atropine slows myopia progression more in Asian than white children by meta-analysis. Optom Vis Sci. 2014; 91: 342-50.

77. Li SM, Li H, Li SY, Liu LR, Kang MT, Wang YP, et al. Time Outdoors and Myopia Progression Over 2 Years in Chinese Children: The Anyang Childhood Eye Study. Invest Ophthalmol Vis Sci. 2015; 56: 4734-40.

78. Li SM, Li SY, Kang MT, Zhou Y, Liu LR, Li H, et al. Near Work Related Parameters and Myopia in Chinese Children: the Anyang Childhood Eye Study. PLoS One. 2015; 10: e0134514. 